\title{
Process Modeling of Thermoset Composites used for Wind Blade Manufacturing
}

\author{
Sagar P. Shah ${ }^{\text {a }}$, Sagar U. Patil ${ }^{\text {b }}$ \\ Christopher J. Hansen ${ }^{a}$, Gregory M. Odegard ${ }^{b}$ \\ Marianna Maiarù $^{a *}$ \\ ${ }^{a}$ University of Massachusetts Lowell, Lowell, MA - 01854, USA. \\ ${ }^{b}$ Michigan Technological University, Houghton, MI-49931, USA.
}

* Corresponding Author 


\begin{abstract}
A computational process modeling framework, informed by accurate material characterization, is presented for virtual manufacturing of wind energy thermoset composites. Process modeling simulations of composite microstructures are carried out to predict the in-situ matrix property evolution and performance-altering residual stress generation. To achieve this, a comprehensive material characterization effort is carried out. Consequently, a novel material property dataset for a widely-used wind energy thermoset system is generated as a function of the temperature and degree of cure. Informed by these material properties, the ability of the process model to reliably estimate manufacturing-induced residual stresses is highlighted. For a prescribed cure cycle, the in-situ elastic modulus evolution, chemical and thermal strains, and random fiber distribution are shown to significantly influence the residual stress generation. The results also show that a full process modeling analysis that includes the complete cure cycle (instead of the standard approach of just considering the post-processing cool-down cycle) is necessary to accurately predict manufacturing-induced residual stresses.
\end{abstract}

\title{
Keywords:
}

A. Thermosetting resin

B. Thermomechanical

B. Residual/internal stress

E. Cure 


\section{Introduction}

Polymer matrix composites (PMCs) are finding widespread applications as primary load-bearing components in the wind energy industry due to their desirable properties and high strength-to-weight ratios [1]. However, manufacturing such composites remains a challenging task. The chemo-rheological and thermo-mechanical properties of the constituent matrix evolve as curing progresses. Several multi-physical phenomena, such as chemical shrinkage, exothermic heat generation, and mismatch between constituent material properties, further influence the in-situ matrix response and result in performance-altering residual stress build-up, deformation, and damage during manufacturing [2]-[9]. The extent to which these residual stresses alter the composite performance is not fully understood.

Process modeling simulations informed by accurate and comprehensive material characterization can fill this knowledge gap. The resulting process model can be used to optimize composite manufacturing to improve the performance of composite parts for wind energy applications. Process modeling leverages robust computational analysis tools to enable accurate prediction of the composite microscale response when subjected to various thermo-mechanical loads [2]-[8], [11]-[17]. Numerous computational studies, based on aerospace-grade composites, have reported phenomenological and constitutive relations to predict the evolution of matrix cure [18], estimate the process-induced residual stress generation [19]-[28], and evaluate its effect on the processed composite performance [3]-[6], [8], [11], [12], [29]. However, due to the lack of a complete cure- and temperature-dependent material property dataset, such studies typically rely on room temperature data or employ deterministic matrix properties for their analysis. Consequently, the prediction accuracy of the numerical methods presented in these studies strongly depends on the quality of the input material property dataset [30].

In-depth knowledge of the cure- and temperature-dependent material behavior is critical to fully understand the development of residual stresses within composite materials and accurately quantify their effect on composite part performance [10]. Few studies have reported comprehensive material 
characterization methodologies to accurately and reliably determine the matrix curing kinetics and the development of thermo-mechanical properties as a function of the degree of cure and temperature [10], [30]-[36]. However, these studies are limited to the characterization of aerospace-grade resin systems. Similar material property datasets are extremely scarce for commercial systems used in wind energy applications. Consequently, the implementation of robust process modeling techniques to optimize wind blade manufacturing proves challenging and thus remains unexplored. Therefore, the need for a comprehensive and reliable material property dataset is paramount to facilitate process modeling of wind energy composites for their optimized manufacturing and improved performance and durability.

In this study, a robust computational process modeling framework, informed by comprehensive material characterization, is presented to predict residual stress generation in composite microstructures during manufacturing. Using established characterization procedures typical to aerospace-grade materials, this work presents a novel material property dataset for a widely-used wind energy material system as a function of the degree of cure and temperature. For ease of implementation within the process modeling framework, resin-specific material models are developed that establish the dependence of the resin thermo-mechanical properties on the degree of cure and temperature. Subsequently, finite element (FE)-based process modeling analyses are carried out to predict residual stress generation in composite microstructures subjected to an arbitrary temperature profile. A separate linear-elastic thermal cooldown analysis is performed using constant room temperature material properties. The end-of-cure residual stresses from the process model and the thermal cooldown are compared. The sensitivity of residual stress generation to the material property evolution during manufacturing is thus evaluated.

The manuscript is organized as follows: the material characterization methodology is outlined and the relevant results are discussed in Section 2, the computational model generation and process modeling analysis of composite microstructures are detailed in Section 3, and the main conclusions are elaborated in Section 4. 


\section{Material and Experimental Methods}

\subsection{Material and Manufacturing}

The present research focuses on a low viscosity thermosetting epoxy system developed by Hexion Inc. for wind energy applications. The system, commercially sold as EPIKOTE ${ }^{\mathrm{TM}}$ Resin MGS $^{\mathrm{TM}}$ RIMR 135 with the EPIKURE ${ }^{\mathrm{TM}}$ Curing Agent MSG $^{\mathrm{TM}}$ RIMH 1366 (henceforth referred to as RIM R135/H1366), is a two-part formulation consisting of a base epoxy and an amine-based hardener. This system has a low processing temperature and long gel time, making it an ideal choice for infusion processes popularly used in wind turbine blade manufacturing.

For all the characterization techniques discussed in this section, the resin mixture was prepared at room temperature by thoroughly mixing the RIM R135/H1366 in a stoichiometric ratio of 100:30 parts by weight for two minutes. The mixture was then degassed for a minimum of twenty minutes. Depending on the characterization technique, the uncured mixture was either directly tested for specific properties or injected into molds to prepare the test specimens. Test specimens were cured at a manufacturer-recommended temperature of $80^{\circ} \mathrm{C}$.

\subsection{Cure kinetics}

The resin cure kinetics were measured with a Differential Scanning Calorimeter (DSC Discovery, TA Instruments). For these tests, a small amount of uncured mixture $(6 \pm 2.5 \mathrm{mg})$ was sealed in a hermetic aluminum pan. Before each DSC scan, the pan was equilibrated to $-10^{\circ} \mathrm{C}$ for two minutes to avoid premature curing. Non-isothermal measurements were performed to measure the total exothermic heat of the reaction $H_{\mathrm{T}}$. During these tests, specimens were heated at a constant temperature rate of $10^{\circ} \mathrm{C} / \mathrm{min}$ over a temperature range of $-10^{\circ} \mathrm{C}$ to $300^{\circ} \mathrm{C}$. The total heat of reaction was computed by integrating the area under the normalized heat flow versus temperature plot shown in Figure 1a. 
The relationship between the heat release rate $\mathrm{d} H / \mathrm{d} t$ and the cure time $t$ for a given isothermal cure temperature $T$ was established with isothermal DSC measurements. For these tests, uncured resin specimens were rapidly heated from the equilibration temperature $\left(T_{\text {eq }}=-10^{\circ} \mathrm{C}\right.$ ) to $50^{\circ} \mathrm{C}, 60^{\circ} \mathrm{C}$, and $70^{\circ} \mathrm{C}$ (typical processing conditions based on manufacturer recommendations) and cured for 720 minutes (the time at which full cure is expected). The normalized heat flow versus time plots for the three temperatures, shown in Figure $1 \mathrm{~b}$, were used to compute the instantaneous $\mathrm{d} H / \mathrm{d} t$ and the partial heat of the reaction $H_{\mathrm{pr}}$ up to $t$. The rate of reaction $\mathrm{d} \phi / \mathrm{d} t$ and the degree of cure $\phi$ were determined using

$$
\begin{gathered}
\frac{\mathrm{d} \phi}{\mathrm{d} t}=\frac{1}{H_{\mathrm{T}}} \frac{\mathrm{d} H}{\mathrm{~d} t} \\
\phi=\frac{1}{H_{\mathrm{T}}} \int_{0}^{t} \frac{\mathrm{d} H}{\mathrm{~d} t} \mathrm{~d} t=\frac{H_{\mathrm{pr}}}{H_{\mathrm{T}}}
\end{gathered}
$$

For each value of $T, \mathrm{~d} \phi / \mathrm{d} t$ was expressed as a function of $\phi$ using a phenomenological autocatalytic semi-empirical kinetic model developed by Kamal et al. [18],

$$
\begin{gathered}
\frac{\mathrm{d} \phi}{\mathrm{d} t}=\left(K_{1}+K_{2} \phi^{m}\right)(1-\phi)^{n} \\
K_{\mathrm{i}}=A_{\mathrm{i}} \exp \left(-\frac{\Delta E_{\mathrm{i}}}{R T^{*}}\right) \quad \mathrm{i}=1,2
\end{gathered}
$$

where $K_{1}$ and $K_{2}$ are Arrhenius rate functions, $m$ and $n$ dimensionless and real modeling parameters, $A_{1}$ and $A_{2}$ are pre-exponential factors, $\Delta E_{1}$ and $\Delta E_{2}$ are activations energies, $T^{*}$ is the absolute temperature in Kelvin, and $R$ is the gas constant. For each isothermal cure temperature, $\mathrm{d} \phi / \mathrm{d} t$ and $\phi$ were fitted to Equation (3) using least-squares non-linear regression. Exponents $m$ and $n$ (constants for all isothermal measurements) were determined through trial-and-error in order to obtain the best fits. This yielded the 
relevant rate functions $K_{\mathrm{i}}$ for each isothermal cure temperature. Subsequently, $A_{\mathrm{i}}$ and $\Delta E_{\mathrm{i}}$ were obtained from a linear fitting of the $\ln \left(K_{\mathrm{i}}\right)$ versus $1 / R T^{*}$. These kinetic constants are summarized in Table 1 .

The derived model predictions were superimposed onto the experimental $\mathrm{d} \phi / \mathrm{d} t$ versus $\phi$ curves computed using Equations (1) and (2) in Figure 2a. A strong match was observed between the experiments and model predictions. To gauge the model's accuracy, partially cured specimens were tested under dynamic conditions to determine their degrees of cure. The kinetic model was very accurate in predicting the final cure state of these specimens, as shown in Figure 2b.

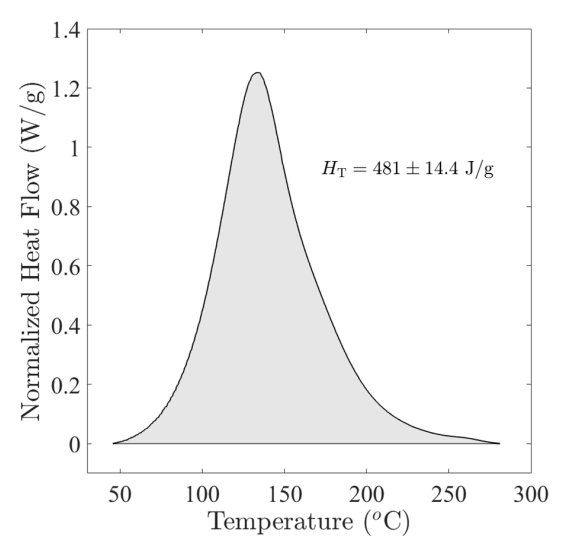

(a)

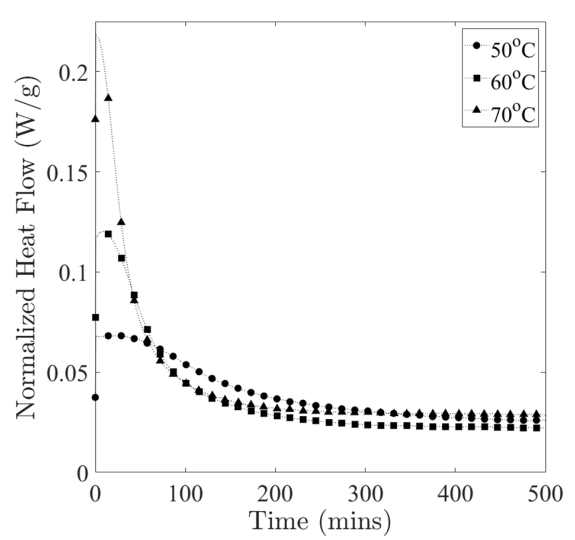

(b)

Figure 1: Normalized heat flow versus (a) temperature plot from a non-isothermal DSC measurement and (b) time plot from three independent isothermal DSC measurements.

Table 1: Summary of the kinetic constants determined from isothermal DSC measurements of RIM R135/H1366 epoxy system.

\begin{tabular}{|c|c|c|c|}
\hline \multicolumn{2}{|c|}{ Property } & Value & Unit \\
\hline \multirow{2}{*}{ Exponent } & $m$ & 0.4 & {$[-]$} \\
\hline & $n$ & 1.5 & {$[-]$} \\
\hline \multirow{2}{*}{ Rate constant } & $A_{1}$ & $3.6 \times 10^{9}$ & {$\left[\mathrm{sec}^{-1}\right]$} \\
\hline & $A_{2}$ & 0.01246 & {$\left[\mathrm{sec}^{-1}\right]$} \\
\hline \multirow{2}{*}{ Activation energy } & $\Delta E_{1}$ & 85.3 & {$[\mathrm{~kJ} / \mathrm{mol}]$} \\
\hline & $\Delta E_{2}$ & 11.1 & {$[\mathrm{~kJ} / \mathrm{mol}]$} \\
\hline
\end{tabular}




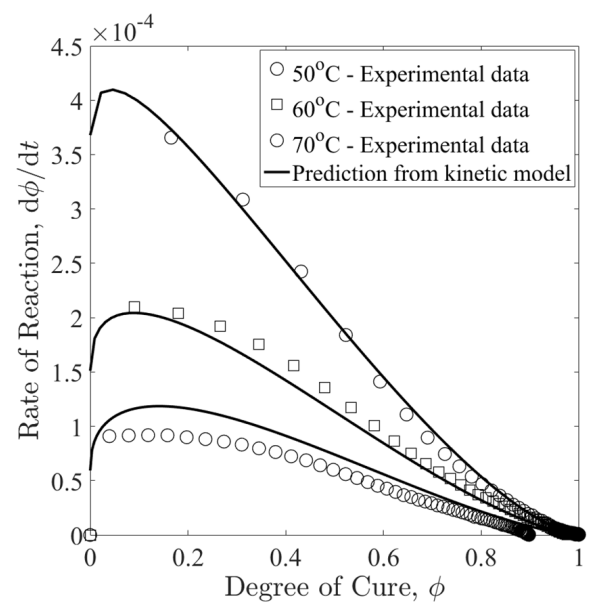

(a)

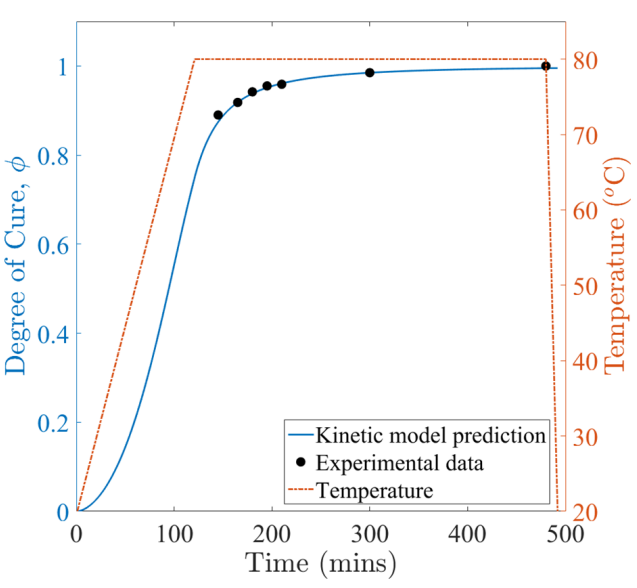

(b)

Figure 2: Comparison of experimental data with the predictions from the autocatalytic cure kinetic model. The plot of (a) the rate of reaction versus degree of cure computed from isothermal DSC measurements and (b) degree of cure and temperature versus time obtained from non-isothermal DSC measurements.

\subsection{Glass Transition Temperature}

The resin glass transition temperature $T_{\mathrm{g}}$ was determined using dynamic DSC. During the test, the normalized heat flow was measured as a function of the test temperature. A discontinuity in the slope of the normalized heat flow was regarded as the glass transition temperature.

For these tests, uncured resin specimens were sealed in hermetic pans and cured under isothermal conditions at $80^{\circ} \mathrm{C}$ for several time intervals to attain intermediate cure levels. Following the isothermal cure, the specimens were rapidly cooled to $-70^{\circ} \mathrm{C}$ to stop further curing. The specimens were subsequently subjected to a dynamic temperature sweep from $-70^{\circ} \mathrm{C}$ to $300^{\circ} \mathrm{C}$ at a temperature rate of $10^{\circ} \mathrm{C} / \mathrm{min}$. Figure 3a shows the normalized heat flow versus temperature plot for partially cured specimens. The mid-point of the step-change in the normalized heat flow versus temperature plot (marked with arrows) was regarded as $T_{\mathrm{g}}^{\phi}$. The residual heat of the reaction $H_{\mathrm{rs}}$ following the glass transition phase was used to determine the degree of cure using 


$$
\phi=1-\frac{H_{\mathrm{rs}}}{H_{\mathrm{T}}}
$$

The evolution of the glass transition temperature with the degree of cure is presented in Figure $3 b$. This evolution of $T_{\mathrm{g}}^{\phi}$ with $\phi$ was modeled with the DiBenedetto equation [37],

$$
\frac{T_{\mathrm{g}}^{\phi}-T_{\mathrm{g}}^{0}}{T_{\mathrm{g}}^{1}-T_{\mathrm{g}}^{0}}=\frac{\lambda \phi}{1-(1-\lambda) \phi}
$$

where $T_{\mathrm{g}}^{0}=-53.2^{\circ} \mathrm{C}$ and $T_{\mathrm{g}}^{1}=85.6^{\circ} \mathrm{C}$ are the glass transition temperatures of the uncured and fully cured resin, $T_{\mathrm{g}}^{\phi}$ is the glass transition temperature for an intermediate degree of cure $\phi$, and $\lambda$ is a dimensionless fitting parameter used to obtain the best fit. For this material system, $\lambda=0.2373$. This model accurately predicted the evolution of the glass transition temperature with an $R^{2}$-value of 0.999 . The glass transition temperatures obtained by two other methods, thermo-mechanical analysis (TMA) and dynamic mechanical analysis (DMA, discussed below), were also compared to the predicted temperature as shown in Figure $3 \mathrm{~b}$.

The DiBenedetto equation predictions of the $T_{\mathrm{g}}^{\phi}$ agreed well with the measured values from the TMA and DMA methods. The $T_{\mathrm{g}}$ values between the testing methods were expected to differ marginally since the glass transition passage does not affect the thermodynamic and mechanical properties at the same point, but rather occurs over a range of temperatures [34], [38].

\subsection{Gelation}

The time to gelation $t_{\text {gel }}$ was measured with a rotational rheometer (ARES-G2, TA Instruments). The uncured resin mixture, prepared at room temperature, was injected between the parallel plates with an initial gap of $h_{0}=1.5 \pm 0.05 \mathrm{~mm}$. The mixture was then rapidly heated to $80^{\circ} \mathrm{C}$. To avoid temperature-induced volumetric changes in the test specimen, the tests were carried out under isothermal conditions at $80^{\circ} \mathrm{C}$. 


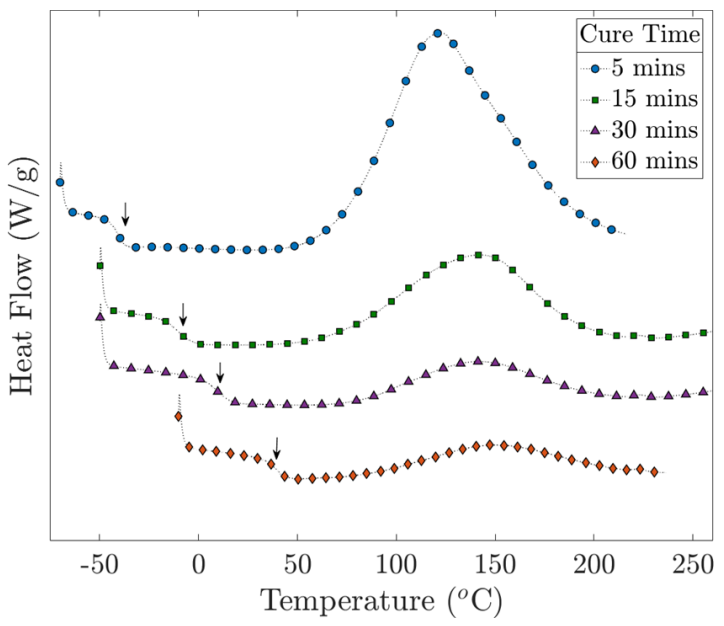

(a)

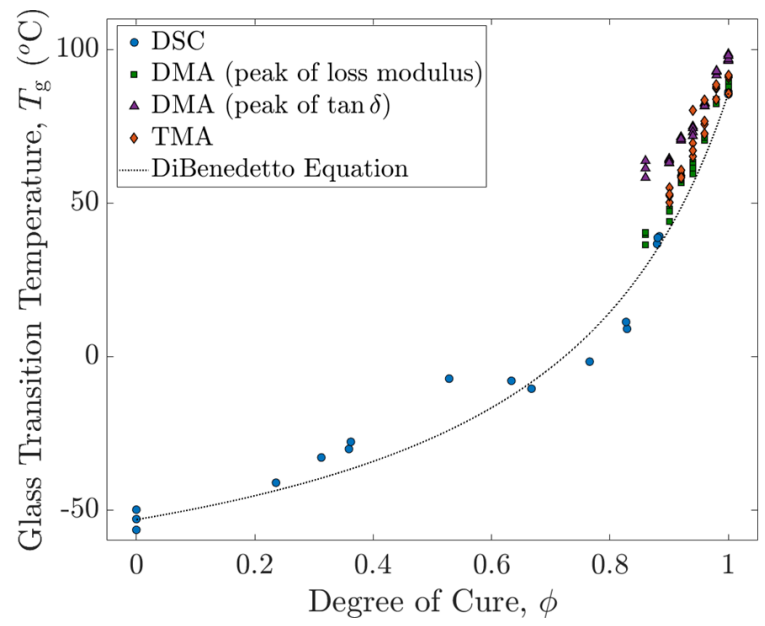

(b)

Figure 3: Plot of (a) normalized heat flow versus temperature from dynamic DSC measurements of partially cured specimens and (b) glass transition temperature versus degree of cure computed as the mid-point of the step-change, model fitting obtained from the DiBenedetto equation.

For these tests, the rheometer was set in gap control mode, which meant the instrument maintained a constant gap of $h_{0}$ for the duration of the test. As the resin cured, it was subjected to an oscillating shear strain $\gamma$ with a maximum value of $200 \%$ and an oscillating frequency of $1 \mathrm{~Hz}$. The storage modulus $G^{\prime}$ and the loss modulus $G^{\prime \prime}$ are components of the complex shear modulus $G$, which relates the applied $\gamma$ to the measured shear stress $\tau$. Their evolution, as a function of the $t$, for one isothermally-cured test specimen is shown in Figure 4. The crossover between $G^{\prime}$ and $G^{\prime \prime}$, which indicates that the resin has sufficiently solidified to transfer stresses, was used to determine the resin gel point. This crossover occurred approximately at $t_{\mathrm{gel}}=38$ minutes of isothermal curing at $80^{\circ} \mathrm{C}$. Considering the time-temperature history of the rheology test, the degree of cure corresponding to $t_{\text {gel }}$ was calculated from the kinetic model given by Equation (3). The average gel point from the three tests $\phi_{\text {gel }}=0.78$. Literature studies on other RTM resin systems have reported similar gel point values [31], [34], [39]-[42]. 


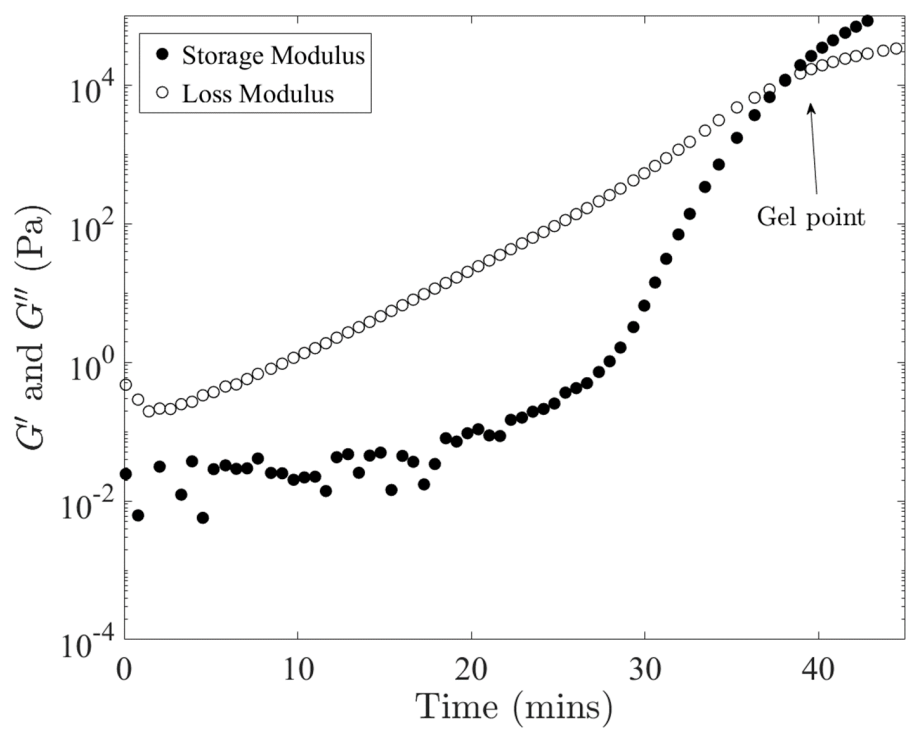

Figure 4: Plot showing the evolution of the storage and the loss moduli as a function of cure time. The crossover between storage and loss moduli is defined as the gel point.

\subsection{Chemical Shrinkage}

The post-gelation volumetric chemical shrinkage $\epsilon_{\mathrm{sh}}^{\phi}$ was measured using the same rheometer setup as the gel point measurement. The test procedure for the shrinkage measurement was divided into two steps. The first step was identical to the gel point measurement where the instrument operated in gap control mode. During this step, the liquid resin was allowed to cure under zero normal force $F_{\mathrm{N}}$ when $t<t_{\text {gel }}$. The complex viscosity measured during this step was used to switch from gap control mode to force control mode when $t=t_{\mathrm{gel}}$. During the second step, the instrument applied a constant $F_{\mathrm{N}}=0.1 \mathrm{~N}$ to maintain contact between the shrinking specimen and the plates. Additionally, a maximum torque of $100 \mathrm{mN}$ was applied at a $30 \mathrm{~Hz}$ frequency. The steady decrease in the gap distance $(h)$ resulting from chemical shrinkage in the specimen, was monitored by the instrument.

The decrease in $h$ relative to the $t$ is presented in Figure 5. When $t<t_{\mathrm{gel}}, h$ remained constant with a value of $h_{0}$ indicating a gap control mode operation. When $t=t_{\mathrm{gel}}$, the instrument switched to a force 
control mode and applied a $F_{\mathrm{N}}=0.1 \mathrm{~N}$. This caused a sudden decrease in $h$, as seen in Figure 5. Upon stabilizing, $h$ steadily decreased as the specimen volume reduced due to chemical crosslink formation. The specimens were allowed to cure for an additional 120 minutes after gelation. By then, the specimens were expected to be fully cured and additional change in $h$ was found to be insignificant. Neglecting the decrease in $h$ due to the application of $F_{\mathrm{N}}$, the post-gelation volumetric chemical shrinkage $\epsilon_{\mathrm{sh}}$ was computed using

$$
\epsilon_{\mathrm{sh}}=\left[1+\frac{1}{3}\left(\frac{h-h_{0}}{h_{0}}\right)\right]^{3}-1
$$

This relationship assumes the in-plane strains in the specimen are zero and the material is incompressible $(v=0.5)[40]$. The chemical shrinkage as a function of the cure time for three isothermally cured test specimens is shown in Figure 6a. The average post-gelation volumetric shrinkage for a fully cured specimen $\epsilon_{\mathrm{sh}}^{1}=2.1 \pm 0.07 \%$. This value was within the typical range of shrinkage values observed in the literature $(2-7 \%)$ for epoxy systems [34], [43], [44]. Based on the time-temperature history of the test, the degree of cure was computed using Equation (3). The chemical shrinkage as a function of the degree of cure is presented in Figure 6b. $\epsilon_{\mathrm{sh}}^{\phi}$ was modeled as a linear function of $\phi$

$$
\epsilon_{\mathrm{sh}}^{\phi}=\left\{\begin{array}{cl}
0, & \phi \leq \phi_{\mathrm{gel}} \\
\beta\left(\phi-\phi_{\mathrm{gel}}\right), & \phi>\phi_{\text {gel }}
\end{array}\right.
$$

where $\beta$ is the shrinkage coefficient determined using the least square linear regression of chemical shrinkage versus time curves. For this material system, $\beta=0.111$.

\subsection{Coefficient of Thermal Expansion}

The post-gelation coefficient of thermal expansion (CTE) $\alpha_{\mathrm{i}}^{\phi}$ of the RIM R135/H1366 epoxy was measured using a TMA (Q400, TA Instruments). The TMA employs a highly sensitive expansion probe to measure the through-thickness dimension changes $\Delta h$ in the specimen relative to the temperature. 


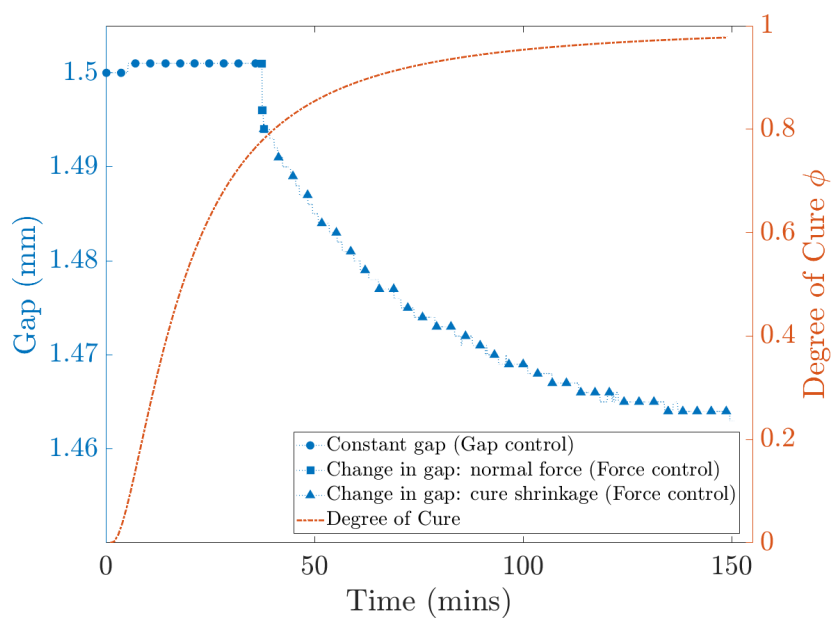

Figure 5: Plot showing the variation in the gap between the parallel plates (circular, square, and triangular symbols in blue) during various phases of the test and the evolution of the degree of cure (dot-dash curve in orange).

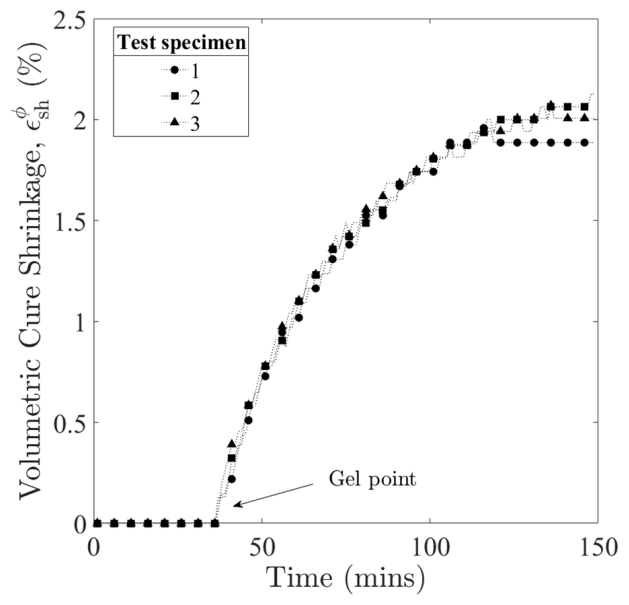

(a)

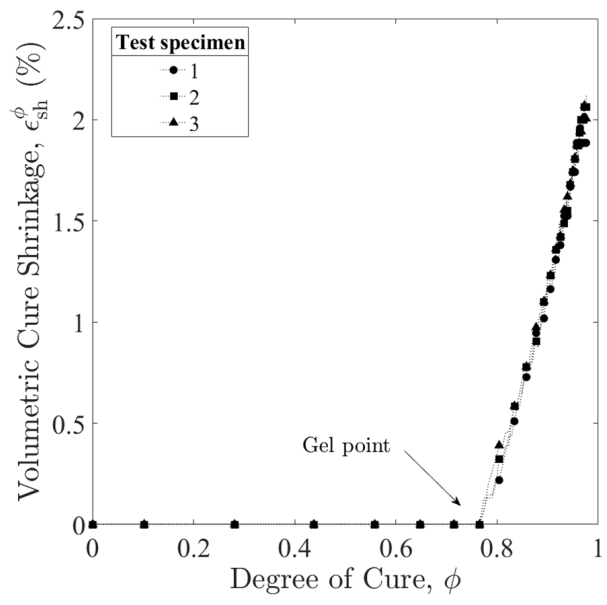

(b)

Figure 6: Evolution of the measured volumetric chemical shrinkage under isothermal conditions as a function of (a) time and (b) degree of cure.

The test specimens were prepared in an open mold. The degassed mixture was injected into the mold, which was then transferred into a convection oven that was programmed to run the manufacturerrecommended cure cycle. Specimens were allowed to cure in the oven until the target degrees of cure were 
achieved. The specimens were removed from the oven and rapidly cooled to arrest further curing. The specimens were then cut into 3-4 mm cubes and polished to achieve top and bottom surfaces that were flat and parallel for the probe to rest on [45]. The specimens were placed in the TMA furnace which was equilibrated at $20^{\circ} \mathrm{C}$ and heated at a constant rate of $5^{\circ} \mathrm{C} / \mathrm{min}$ to $130^{\circ} \mathrm{C}$. An $F_{\mathrm{N}}=0.01 \mathrm{~N}$ was applied for the entire duration of the test to maintain contact with the specimen. As the specimen was heated, the probe measured the through-thickness dimension change $\Delta h$ in the specimen as a function of the temperature $T$.

The CTE is defined as the relative change in the specimen dimension $\Delta h / h_{0}$ with respect to the change in the temperature $\Delta T$ [34], [45]. This value was obtained as the slope of the relative dimension change versus the temperature plot generated by the TMA. Figure 7 a shows one such plot for a fully cured specimen. A distinct linear region between $40^{\circ} \mathrm{C}$ and $80^{\circ} \mathrm{C}$ (region I) was observed, followed by a transition region between $80^{\circ} \mathrm{C}$ and $95^{\circ} \mathrm{C}$ (gray area), where the slope changed. After this transition region, a second linear region was observed between $95^{\circ} \mathrm{C}$ and $110^{\circ} \mathrm{C}$ (region II). The transition region represented the material's physical transition from a glassy state to a rubbery state as it was heated, and the inflection point was defined as the $T_{\mathrm{g}}$. The slopes of the plot before and after the transition region corresponded to the preand post-transition CTE. The specimen registered a $T_{\mathrm{g}}^{1}=91.2^{\circ} \mathrm{C}$. The pre-transition CTE was $\alpha_{\mathrm{I}}^{1}=7.39$ $\times 10^{-5} /{ }^{\circ} \mathrm{C}$ while the post-transition CTE was $\alpha_{\text {II }}^{1}=17.1 \times 10^{-5} /{ }^{\circ} \mathrm{C}$.

The variation in the post-gelation CTE is illustrated as a function of $\phi$ in Figure $7 \mathrm{~b}$. For $T<T_{\mathrm{g}}^{\phi}, \alpha_{\mathrm{I}}^{\phi}=$ $(7.92 \pm 0.538) \times 10^{-5} /{ }^{\circ} \mathrm{C}$ was obtained. This value did not change with $\phi$. By contrast, above $T_{\mathrm{g}}$, the material registered a CTE value ranging from $\alpha_{\mathrm{II}}^{\phi}=(18.95 \pm 0.86) \times 10^{-5} /{ }^{\circ} \mathrm{C}$ for $\phi=0.9$ to $\alpha_{\mathrm{II}}^{\phi}=$ $(16.86 \pm 0.21) \times 10^{-5} /{ }^{\circ} \mathrm{C}$ for $\phi=1$. A $11 \%$ drop was observed in the material CTE with an increasing degree of cure which was attributed to crosslink network formation, which restricts molecular mobility as cure progresses. The variation in the post-gelation CTE with the degree of cure and glass transition temperature was defined using 


$$
\alpha_{\mathrm{i}}^{\phi}= \begin{cases}7.93 \times 10^{-5}, & T \leq T_{\mathrm{g}}^{\phi} \\ {\left[a-b\left(\phi-\phi_{\text {gel }}\right)\right] \times 10^{-5},} & T>T_{\mathrm{g}}^{\phi}\end{cases}
$$

where $a$ and $b$ are dimensionless fitting parameters obtained using linear regression. For this material system, $a=21.21$ and $b=18.25$.

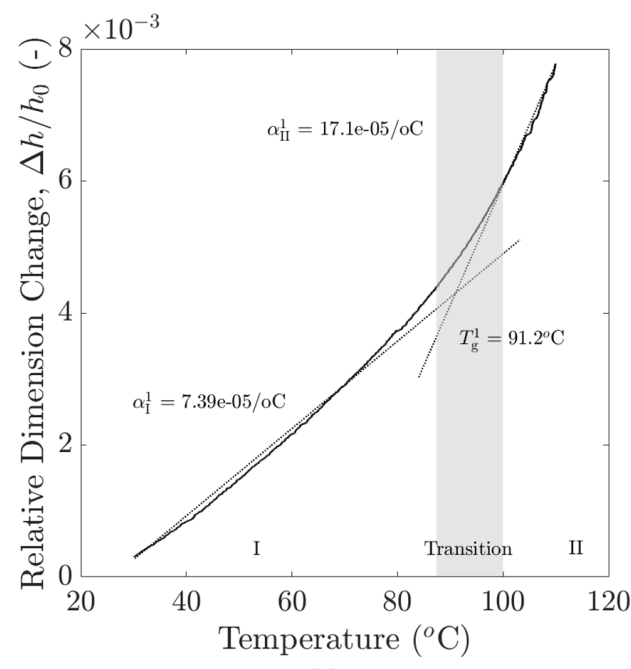

(a)

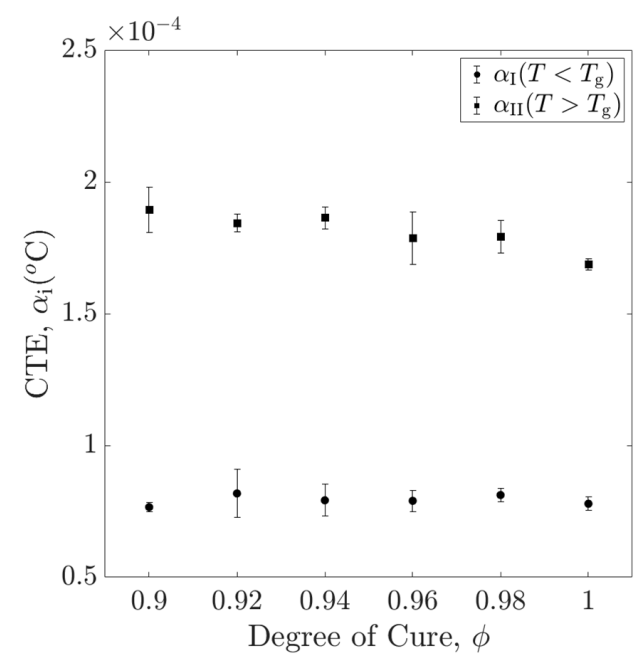

(b)

Figure 7: (a) Relative dimension change as a function of temperature for a fully cured specimen and (b) variation in the coefficient of thermal expansion with the degree of cure before and after the glass transition region.

\subsection{Elastic Modulus}

The variation of the post-gelation elastic modulus $E_{\mathrm{T}}^{\phi}$ with the processing temperature and the degree of cure was characterized with a DMA (Q800, TA Instruments). The test specimens were prepared in a closed mold. The degassed mixtures of resin were injected into the mold, which was then transferred into a convection oven that was programmed to run the manufacturer-recommended cure cycle. Specimens were allowed to cure in the oven until target degrees of cure were achieved. The specimens were removed from 
the oven and rapidly cooled to arrest further curing. The specimens were then cut and polished to conform to the ASTM D7028-07 standard test specimen geometry [46].

During the test, fully cured specimens were mounted in a single cantilever beam configuration inside the DMA chamber. The specimens were first tested isothermally at $20^{\circ} \mathrm{C}$ for 15 minutes by applying an oscillating displacement of $10 \mu \mathrm{m}$ at a $1 \mathrm{~Hz}$ frequency. Following this, a temperature sweep was performed, where the temperature was linearly increased to $120^{\circ} \mathrm{C}$ at a rate of $3^{\circ} \mathrm{C} / \mathrm{min}$. For the entire duration of the test, the instrument measured the storage modulus $E^{\prime}$ and the loss modulus $E^{\prime \prime}$. The complex elastic modulus $E$ was computed using

$$
E=E^{\prime}+i E^{\prime \prime} \rightarrow E=\sqrt{E^{2}+E^{\prime 2}}
$$

The variation in the complex elastic modulus with the temperature for a fully cured specimen $(\phi=1)$ is shown in Figure 8. For the initial 20 minutes of the test, the temperature was held constant, and the specimen registered an $E_{20}^{1}=2482 \mathrm{MPa}$. As the temperature gradually increased, the material elastic modulus began to drop. A sharp drop in the complex elastic modulus was observed close to $85^{\circ} \mathrm{C}$, where the glass transition passage was expected. Past the glass transition window, the material registered a significantly low modulus.

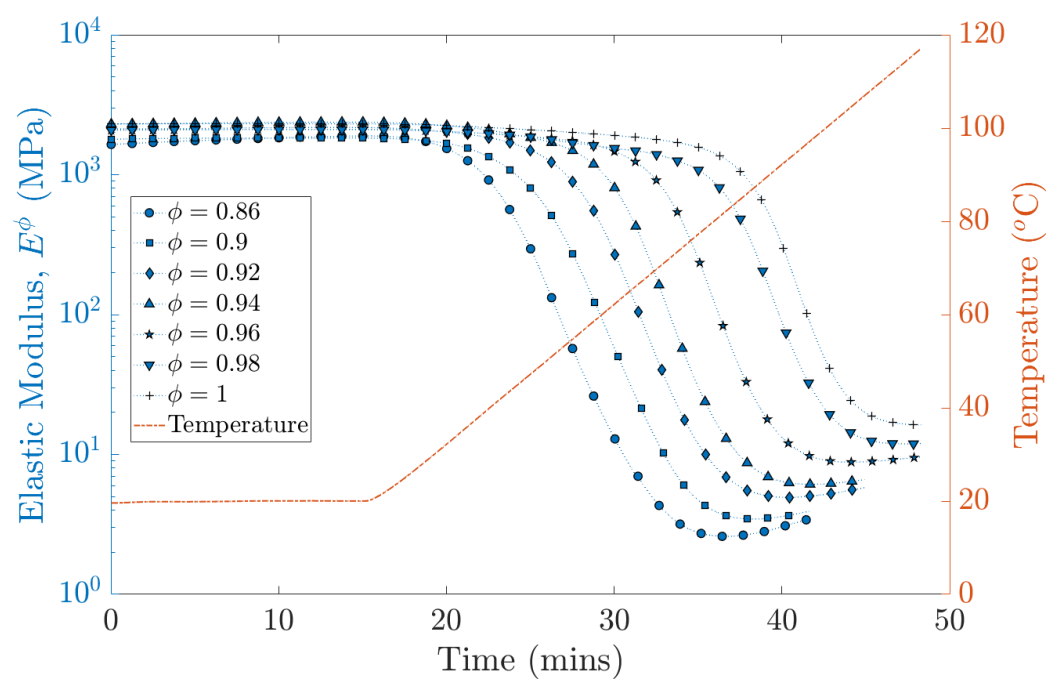

Figure 8: Variation in the matrix elastic modulus with time, temperature, and degree of cure. 
Partially cured specimens were tested under similar test conditions and the evolution of their elastic moduli as a function of the degree of cure and temperature is also presented in Figure 8. It is clear from this plot that all specimens exhibited an elastic modulus close to $2400 \mathrm{MPa}$ at $20^{\circ} \mathrm{C}$. Subsequently, the elastic modulus began to drop as the temperature approached the specimen $T_{\mathrm{g}}^{\phi}$ corresponding to its cure level. This trend suggested that the post-gelation elastic modulus of the vitrified resin $\left(T<T_{\mathrm{g}}^{\phi}\right)$ had a low sensitivity to the degree of cure. However, as the resin temperature approached its glass transition temperature, which is highly dependent on the degree of cure (see Figure 3b), its elastic modulus dropped significantly. The post-transition elastic modulus, when the resin is in the rubbery state $\left(T \geq T_{\mathrm{g}}^{\phi}\right)$, was highly sensitive to not only the temperature but also the degree of cure (Figure 8). Therefore, the effect of temperature and the degree of cure on the elastic modulus should be carefully accounted for during process modeling analysis.

To model this complex dependence of the elastic modulus on the degree of cure and temperature, an approach consisting of a dimensionless, normalized independent parameter and regression was introduced. The dimensionless parameter $\eta$ is defined as

$$
\eta \equiv 1-\frac{T^{*}}{T_{r}^{*}}
$$

where $T_{r}^{*}$ is the reference temperature in degrees Kelvin, which herein was assigned as the highest temperature for which data was available. The parameter $\eta$ was thus defined to be independent of units and provided a modulus function with direct proportionality to the independent variable, that is, as $\eta$ increases, so does the modulus. Here, according to Figure $8, T_{r}^{*}=393.15 \mathrm{~K}$ (or $120^{\circ} \mathrm{C}$ ) was utilized. The $E$ versus $\eta$ curve was fitted to a sigmoidal function (Boltzmann equation) for all degrees of cure: 


$$
E(\mathrm{MPa})=A_{2}(\phi)+\frac{A_{1}(\phi)-A_{2}(\phi)}{1+\exp \left(\frac{\eta-\eta_{0}(\phi)}{\mathrm{d} \eta(\phi)}\right)}
$$

The data fitting was performed using the Origin Pro [47] analysis tool and the phenomenological parameters $\eta_{0}, \mathrm{~d} \eta, A_{1}$ and $A_{2}$ were all determined as a function of degree of cure:

$$
\begin{gathered}
\eta_{0}=-0.860 \phi+0.955 \\
\mathrm{~d} \eta=0.070 \phi-0.041 \\
A_{1}(\phi)=-10^{-13} \exp (34.55 \phi) \\
A_{2}(\phi)=1471.3 \phi+801.39
\end{gathered}
$$

This set of equations can be used to compute $E$ at arbitrary cure levels and temperatures.

\section{Computational Micromechanics}

Computational studies of composite microstructures traditionally assume that the thermo-mechanical response of composite material can be determined by analyzing a Repeating Unit Cell (RUC). A unit cell can be termed as a representative volume element (RVE) if the cell is large enough to capture the intended physical mechanisms that influence the composite response without any boundary effects [8]. A convergence analysis must be carried out to determine the appropriate size of the RVE for a particular microstructure. The results of a size effect study performed previously [8] were used for the current study. The micromechanical and process modeling details are discussed in the following sections.

\subsection{RVE Generation}

In this study, RVEs comprising a random dispersion of glass fibers (fiber diameter, $d_{\mathrm{f}}=14 \mu \mathrm{m}$ ) in a RIM R135/H1366 epoxy matrix were generated with a random RVE generator that was developed in-house with MATLAB. Here, 40 fiber RVEs with a fiber volume fraction $v_{\mathrm{f}}=0.55$ were used. Perfect bonding 
was assumed between the fiber and the matrix. Five distinct renditions of the 40 fiber RVE were analyzed, as shown in Figure 9. The fibers were modeled as isotropic linear-elastic solids, the thermo-mechanical properties of which are summarized in Table 2. The matrix was modeled as an isotropic material. The material-specific models described above were used to define the matrix behavior during curing. The process modeling and thermal cooldown analysis were carried out with the commercial FE code Abaqus/STANDARD, supplemented with user-written UMATHT and UMAT [48] subroutines. Each RVE was meshed with C3D8T elements (eight-node, brick elements with temperature degrees of freedom) [48]. Flat Boundary Conditions (FBCs) were chosen over Periodic Boundary Conditions (PBCs) due to their efficient and low-cost implementation [8].

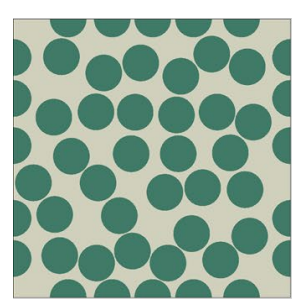

(a)

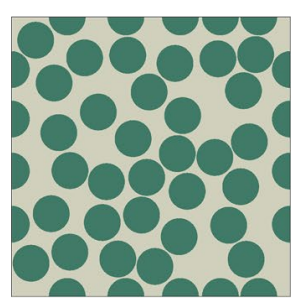

(b)

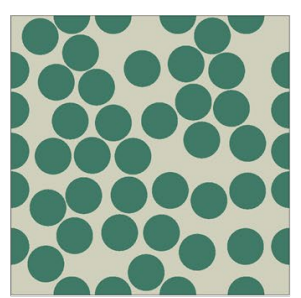

(c)

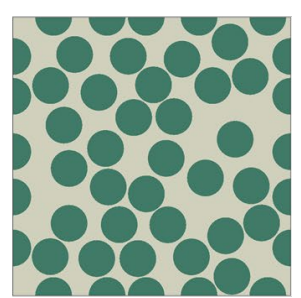

(d)

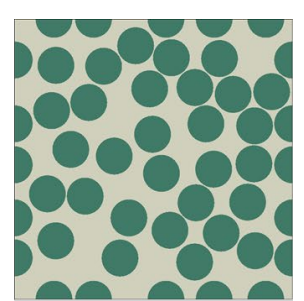

(e)

Figure 9: Five distinct realizations of 40 fiber composite microstructures generated by the random RVE generator.

Table 2: Constituent thermo-mechanical properties of E-glass fiber.

\begin{tabular}{lccc}
\hline \multicolumn{1}{c}{ Property } & & Value & Unit \\
\hline Density & $\rho^{\mathrm{f}}$ & 2,550 & {$\left[\mathrm{~kg} / \mathrm{m}^{3}\right]$} \\
Elastic Modulus & $E_{11}^{\mathrm{f}}=E_{22}^{\mathrm{f}}=E_{33}^{\mathrm{f}}$ & 73,000 & {$[\mathrm{MPa}]$} \\
Poisson's ratio & $v_{12}^{\mathrm{f}}=v_{13}^{\mathrm{f}}=v_{23}^{\mathrm{f}}$ & 0.22 & {$[-]$} \\
Shear Modulus & $G_{12}^{\mathrm{f}}=G_{13}^{\mathrm{f}}=\mathrm{G}_{23}^{\mathrm{f}}$ & 30,000 & {$[\mathrm{MPa}]$} \\
Coefficient of Thermal & $\alpha_{11}^{\mathrm{f}}=\alpha_{22}^{\mathrm{f}}=\alpha_{33}^{\mathrm{f}}$ & $5 \times 10^{-6}$ & {$\left[\mathrm{~K}^{-1}\right]$} \\
Expansion & $k^{\mathrm{f}}$ & 1.2 & {$[\mathrm{~W} / \mathrm{m}-\mathrm{K}]$} \\
Thermal Conductivity & $c_{\mathrm{p}}^{\mathrm{f}}$ & 800 & {$[\mathrm{~J} / \mathrm{kg}-\mathrm{K}]$} \\
Specific Heat & & & \\
\hline
\end{tabular}




\subsection{Process Modeling}

The process modeling replicated the complete manufacturing of the composites by accounting for (a) kinetic progression of the cure which was quantified by $\phi$ and (b) the evolution of the in-situ thermomechanical matrix properties which led to residual stress generation. The progression of the cure for a prescribed temperature profile was defined by Equation (3) and the kinetic constants summarized in Table 1. A coupled temperature-displacement analysis was carried out in Abaqus/STANDARD with usersubroutines UMATHT and UMAT [48]. The kinetic model was solved simultaneously with the 3dimensional Fourier heat transfer model to predict the progression of cure and the temperature distribution as a result of the exothermic heat of reaction. Figure 10 shows the prescribed cure cycle for virtual manufacturing of the composite microstructure along with the computed degree of cure.

The evolution of the in-situ matrix properties and residual stress generation was modeled with a UMAT user subroutine [48]. For a given cure state, the instantaneous material properties were computed with the help of the material models described above. Residual stress generation was then modeled with an instantaneous linear-elastic constitutive model [4], [8],

$$
\sigma_{\mathrm{i}}(t)=\left[C_{\mathrm{ij}}(t)\right]\left[\epsilon_{\mathrm{j}}^{\text {total }}(t)-\left(\epsilon_{\mathrm{j}}^{\mathrm{th}}(t)+\epsilon_{\mathrm{j}}^{\mathrm{sh}}(t)\right) \delta_{\mathrm{j}}\right] \text { where, } \begin{cases}\delta_{\mathrm{j}}=1 & \text { if } \mathrm{j}=1,2,3 \\ \delta_{\mathrm{j}}=0 & \text { if } \mathrm{j}>3\end{cases}
$$

where $\mathrm{i}$ and $\mathrm{j}$ are Voigt notation indices; $\epsilon_{\mathrm{j}}^{\mathrm{total}}(t), \epsilon_{\mathrm{j}}^{\mathrm{th}}(t)$ and $\epsilon_{\mathrm{j}}^{\mathrm{sh}}(t)$ are the total, thermal, and chemical shrinkage strains, respectively; $C_{\mathrm{ij}}(t)$ is the stiffness matrix as a function of the time of cure; $\sigma_{\mathrm{i}}(t)$ is the accumulated residual stress governed by the development of the in-situ matrix elastic modulus and the chemical and thermal strains experienced by the matrix. 


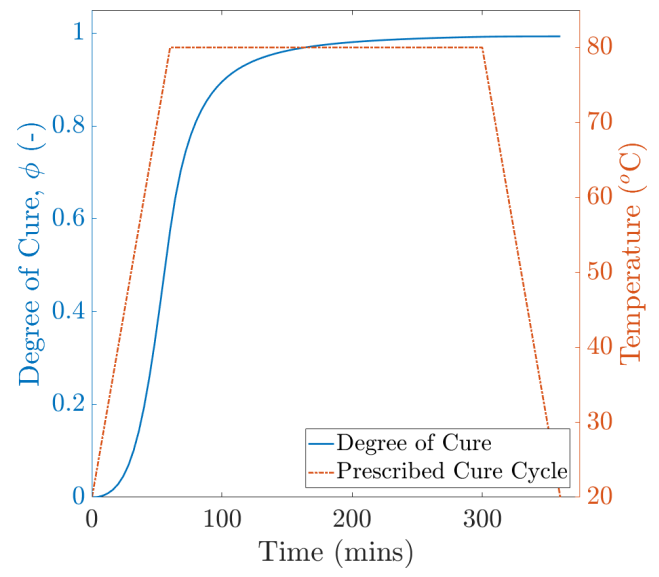

Figure 10: (a) Evolution of the degree of cure as a function of the applied cure cycle.

The evolution of the in-situ matrix elastic modulus in a representative RVE with the degree of cure and temperature is shown in Figure 11a. Figures 11 (b)-(d) show the development of residual stresses with the time of cure at three distinct points in the same RVE resulting from the elastic modulus evolution and volumetric strains experienced by the matrix. In Figure 11a, the pre-gelation epoxy matrix $\left(\phi \leq \phi_{\text {gel }}\right)$ exhibits a very low elastic modulus. Therefore, no significant residual stress generation is observed in Figures 11 (b)-(d) during the pre-gelation phase, even though the matrix experienced thermal and shrinkage strains during the initial heating and isothermal hold stages of the cure cycle, respectively. However, the formation of sufficient crosslink networks led to a rapid increase in the material elastic modulus postgelation, as seen in Figure 11a. A high post-gelation elastic modulus combined with chemical shrinkage strains during the isothermal cure stage and thermal strains during the cooldown stage of the cure cycle resulted in a maximum residual stress generation of $20.28 \mathrm{MPa}$ at point 3 in the RVE, as seen in Figure 11(d). The representative RVE registered volume-average residual stress of 7.6 $\mathrm{MPa}$. 


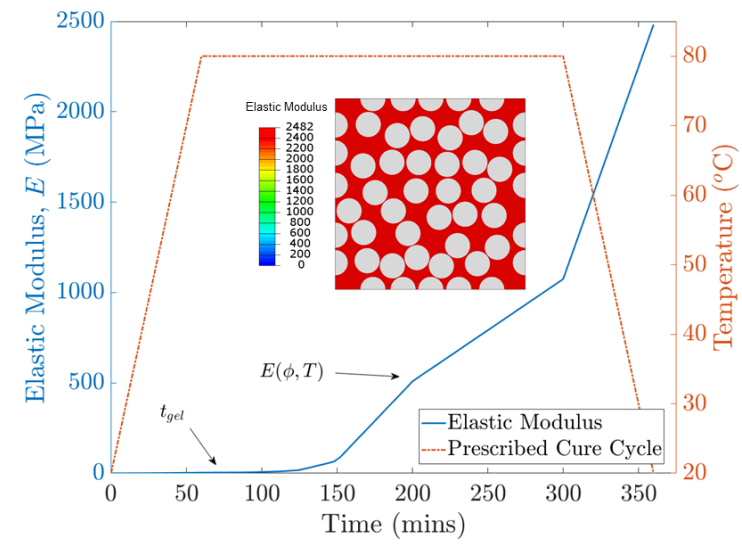

(a)

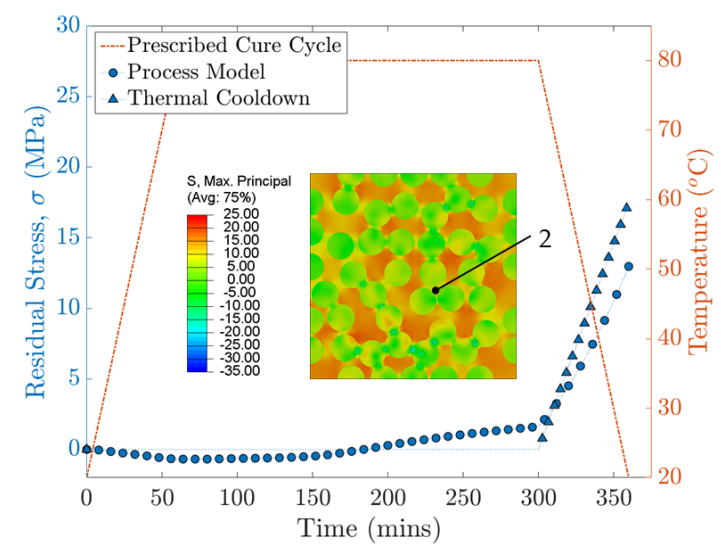

(c)

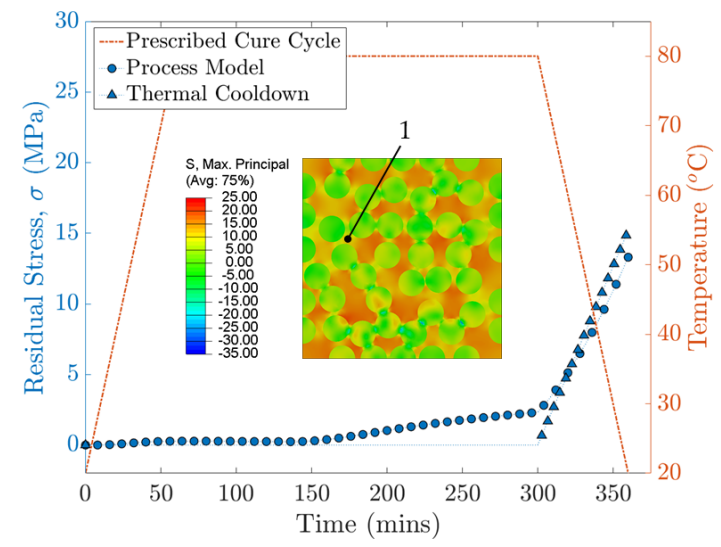

(b)

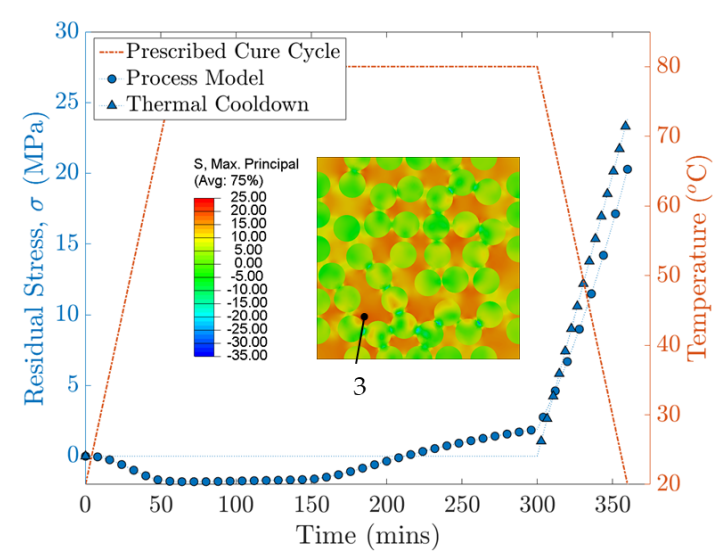

(d)

Figure 11: (a) Evolution of the matrix elastic modulus as a function of the prescribed cure profile and degree of cure for process modeling analysis and development of residual stresses (max. principal) at (b) point 1, (c) point 2, and (d) point 3 within an RVE for process modeling and thermal cooldown analysis.

The residual stresses were also sensitive to the local fiber packing. Figures 11 (b)-(d) show a variation in the magnitude of the residual stresses at three distinct points within a representative RVE. Owing to the random fiber distribution, the end-of-cure residual stresses at three points within the RVE varied between 12.95 MPa and 20.28 MPa. To further illustrate the influence of random fiber packing on residual stress generation, the contour plots of the end-of-cure maximum principal stress for each of the 40-fiber RVEs are presented in Figures 12 (a)-(e). The figures demonstrate a considerable difference in the distribution of 
the residual stresses owing to the unique fiber packing topology in each RVE. Between the RVEs, there was a maximum and volume-average end-of-cure residual stress of $20.45 \pm 0.25 \mathrm{MPa}$ and $7.56 \pm 0.28$ $\mathrm{MPa}$, respectively.

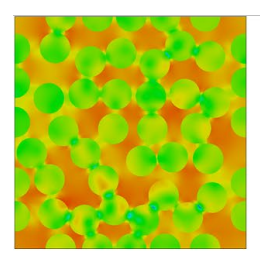

(a)

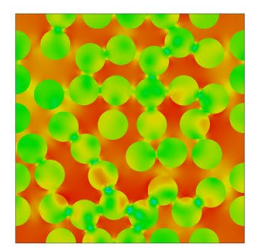

(f)

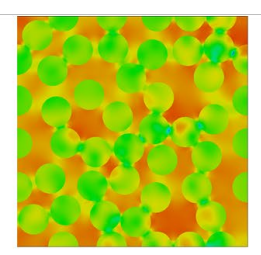

(b)

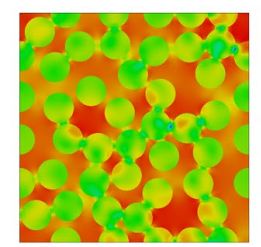

(g)

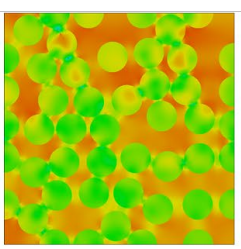

(c)

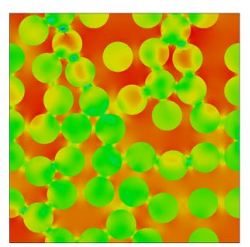

(h)

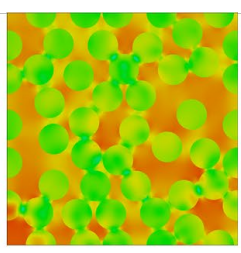

(d)

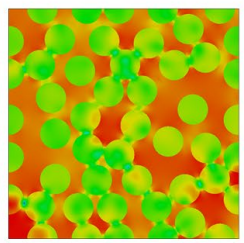

(i)

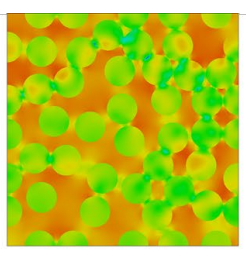

(e)

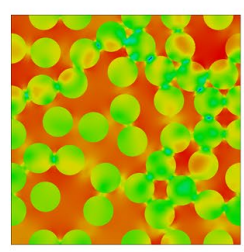

(j)

S, Max. Principal (Avg: 75\%)

25.00
-20.00
15.00

15.00

15.00

$\begin{array}{r}5.00 \\ \hline+\quad 0.00 \\ \hline-5.00 \\ \hline-10.00 \\ \hline\end{array}$

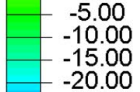

$-20.00$

$-30.00$

$-35.00$

Figure 12: Contour plots of the end-of-cure residual stresses (maximum principal) obtained from (a)-(e) process modeling analysis and (f)-(j) thermal cooldown analysis.

\subsection{Thermal Cooldown Analysis}

Simple thermal cooldown analyses are typically employed to estimate the end-of-cure residual stresses in composites when extensive material property characterization and computational modeling are not feasible. These analyses only consider the final cooling stage of the primary curing cycle during which the matrix material is expected to be fully cured and is gradually cooled from the processing temperature to room temperature. Consequently, the progression of cure, matrix elastic property evolution, and chemical shrinkage strains are ignored in such analyses, and only differential thermal volumetric changes experienced by the constituent fiber and matrix are thus assumed to contribute to the total residual stress generation. A comparison of the end-of-cure residual stresses from the full process model described herein and a simple thermal cooldown analysis can quantify the contributing sources that influence residual stress generation. 
To perform a thermal cooldown analysis in FE, constant room temperature matrix properties corresponding to the fully cured state were allotted to the RVEs shown in Figure 9 with a prescribed linear cooldown from $80^{\circ} \mathrm{C}$ to $20^{\circ} \mathrm{C}$. The residual stress evolution during the thermal cooldown analysis at the same three points in the representative RVE is overlayed on the process modeling results in Figures 11 (b)(d). As seen in the figure, the residual stresses increased linearly at each point as the RVE temperature decreased from $80^{\circ} \mathrm{C}$ to $20^{\circ} \mathrm{C}$. Stress values as high as $23.84 \mathrm{MPa}$ were predicted in the representative RVE shown in Figure 11(d). Compared to the process modeling results at the same location $\left(\sigma_{\mathrm{rs}}^{\max }=20.28 \mathrm{MPa}\right)$, the thermal cooldown analysis overestimated the maximum residual stresses by $17.5 \%$. Furthermore, the volume-average residual stress over the entire representative RVE from the thermal cooldown analysis was 9.02 MPa. Compared to the process model $\left(\sigma_{\mathrm{rs}}^{\mathrm{avg}}=7.6 \mathrm{MPa}\right)$, the cooldown analysis overestimated the volume-average stress by $18.6 \%$ as well. This overestimation is further evident in Figure 12 which compares the end-of-cure residual stress contour plots from the simple thermal cooldown analysis (Figure 12 (f)-(j)) to those from the full process model (Figure 12 (a)-(e)). The thermal cooldown analyses predicted maximum and volume-average residual stresses of $25.2 \pm 0.6 \mathrm{MPa}$ and $9.03 \pm 0.3 \mathrm{MPa}$, respectively. These values were $23.2 \%$ and $19.4 \%$ higher than the maximum and volume-average stresses reported by the full process model, respectively.

From these results, it is clear that simple thermal cooldown analyses for this material fail to accurately predict the process-induced residual stress. In addition to ignoring the mechanical property evolution and chemical shrinkage during curing, the higher initial CTE, which gradually decreases as the cure progresses, may cause significant volumetric expansion during the initial heating stage of the cure cycle, which was also not accounted for. Thus, a combination of low elastic modulus, high initial volumetric expansion, and chemical shrinkage result in non-negligible residual stress generation. Therefore, reliable predictions of residual stress development are not possible with the simple thermal cooldown analysis approach. With the full process modeling approach, the evolution of cure- and temperature-dependent material properties, as 
well as thermal and chemical shrinkage strain predictions, are possible for any prescribed cure cycle. This implies that the process modeling analysis developed herein can be employed to tailor the prescribed cure cycles to mitigate residual stress generation or to achieve a desired internal stress state for enhanced composite part performance.

\section{Conclusions}

This work expands the premise of composite process modeling to wind energy applications. A robust and reliable computational process modeling framework was presented to facilitate virtual manufacturing of composite microstructures and accurate residual stress prediction during their manufacturing. Using established characterization procedures typical to aerospace-grade materials, this work presented a novel material property dataset for a wind energy material system as a function of the cure and temperature. Informed by these accurately measured material properties, the ability of process modeling tools to reliably estimate the manufacturing-induced local residual stress distribution within composite microstructures was highlighted.

Process modeling techniques such as those presented in this research can greatly benefit the efforts to reduce the generation of residual stresses or to achieve the desired internal stress state for enhanced composite part performance. Optimization studies can be performed with process models to assess the influence of each processing parameter, such as the heating rate, hold temperature, and cooling rate on the

final stress state. This in turn will provide optimization opportunities and facilitate the establishment of rapid, reliable, and cost-effective manufacturing procedures. 


\section{Acknowledgments}

This material is based upon the work supported partially by the National Science Foundation under grant number IIP - 1362022 (Collaborative Research: IUCRC for Wind Energy, Science, Technology and Research) and the Air Force Office of Scientific Research and the National Science Foundation under grant number IIP - 1826232. Any opinions, findings and conclusions or recommendations expressed in this material are those of the author(s) and do not necessarily reflect the views of the National Science Foundation. The authors would like to thank NASA for their support of this research under grant numbers 80NSSC19K1246 and NNX17AJ32G. The authors would like to acknowledge the WindSTAR Industrial Advisory Board (IAB) members Steve Nolet, Amir Salimi (TPI Composites Inc.) for their technical contributions and Paul Ubrich, Nathan Bruno, Mirna Robles (Hexion Inc.) for their technical insight to the project and providing the resin material.

\section{References}

[1] J. Galos, "Thin-ply composite laminates: a review," Composite Structures, vol. 236, p. 111920, Mar. 2020, doi: 10.1016/j.compstruct.2020.111920.

[2] S. Shah and M. Maiaru, "Microscale Analysis of Virtually Cured Polymer Matrix Composites Accounting for Uncertainty in Matrix Properties During Manufacturing," Washington, USA, 2018. doi: $10.12783 /$ asc33/25958.

[3] M. Maiaru, "Effect of uncertainty in matrix fracture properties on the transverse strength of fiber reinforced polymer matrix composites," 2018. doi: 10.2514/6.2018-1901.

[4] M. Maiarù, R. J. D’Mello, and A. M. Waas, "Characterization of intralaminar strengths of virtually cured polymer matrix composites," Composites Part B: Engineering, vol. 149, pp. 285-295, Sep. 2018, doi: 10.1016/j.compositesb.2018.02.018.

[5] R. J. D’Mello, M. Maiarù, and A. M. Waas, "Virtual manufacturing of composite aerostructures," The Aeronautical Journal, vol. 120, no. 1223, pp. 61-81, Jan. 2016, doi: 10.1017/aer.2015.19.

[6] R. J. D'Mello, M. Maiarù, and A. M. Waas, "Effect of the curing process on the transverse tensile strength of fiber-reinforced polymer matrix lamina using micromechanics computations," Integrating Materials, vol. 4, no. 1, pp. 119-136, Dec. 2015, doi: 10.1186/s40192-015-0035-y.

[7] T. S. Mesogitis, A. A. Skordos, and A. C. Long, "Uncertainty in the manufacturing of fibrous thermosetting composites: A review," Composites Part A: Applied Science and Manufacturing, vol. 57, pp. 67-75, Feb. 2014, doi: 10.1016/j.compositesa.2013.11.004. 
[8] S. P. Shah and M. Maiarù, "Effect of Manufacturing on the Transverse Response of Polymer Matrix Composites," Polymers, vol. 13, no. 15, Art. no. 15, Jan. 2021, doi: 10.3390/polym13152491.

[9] I. Baran, K. Cinar, N. Ersoy, R. Akkerman, and J. H. Hattel, "A Review on the Mechanical Modeling of Composite Manufacturing Processes," Archives of Computational Methods in Engineering, vol. 24, no. 2, pp. 365-395, Apr. 2017, doi: 10.1007/s11831-016-9167-2.

[10] Y. Nawab, P. Casari, N. Boyard, and F. Jacquemin, "Characterization of the cure shrinkage, reaction kinetics, bulk modulus and thermal conductivity of thermoset resin from a single experiment," $J$ Mater Sci, vol. 48, no. 6, pp. 2394-2403, Mar. 2013, doi: 10.1007/s10853-012-7026-6.

[11] F. Danzi, D. Fanteria, E. Panettieri, and M. C. Mancino, "A numerical micro-mechanical study on damage induced by the curing process in carbon/epoxy unidirectional material," Composite Structures, vol. 210, pp. 755-766, Feb. 2019, doi: 10.1016/j.compstruct.2018.11.059.

[12] X. Hui, Y. Xu, J. Wang, and W. Zhang, "Microscale viscoplastic analysis of unidirectional CFRP composites under the influence of curing process," Composite Structures, vol. 266, p. 113786, Jun. 2021, doi: 10.1016/j.compstruct.2021.113786.

[13] X. Hui, Y. Xu, and W. Zhang, "An integrated modeling of the curing process and transverse tensile damage of unidirectional CFRP composites," Composite Structures, vol. 263, p. 113681, May 2021, doi: 10.1016/j.compstruct.2021.113681.

[14] C. He et al., "A multiscale elasto-plastic damage model for the nonlinear behavior of 3D braided composites," Composites Science and Technology, vol. 171, pp. 21-33, Feb. 2019, doi: 10.1016/j.compscitech.2018.12.003.

[15] L. Yang, Y. Yan, J. Ma, and B. Liu, "Effects of inter-fiber spacing and thermal residual stress on transverse failure of fiber-reinforced polymer-matrix composites," Computational Materials Science, vol. 68, pp. 255-262, Feb. 2013, doi: 10.1016/j.commatsci.2012.09.027.

[16] J. LLorca et al., "Multiscale Modeling of Composite Materials: a Roadmap Towards Virtual Testing," Advanced Materials, vol. 23, no. 44, pp. 5130-5147, 2011, doi: 10.1002/adma.201101683.

[17] L. G. Zhao, N. A. Warrior, and A. C. Long, "A micromechanical study of residual stress and its effect on transverse failure in polymer-matrix composites," International Journal of Solids and Structures, vol. 43, no. 18, pp. 5449-5467, Sep. 2006, doi: 10.1016/j.ijsolstr.2005.08.012.

[18] M. R. Kamal and S. Sourour, "Kinetics and thermal characterization of thermoset cure," Polymer Engineering \& Science, vol. 13, no. 1, pp. 59-64, 1973, doi: https://doi.org/10.1002/pen.760130110.

[19] A. R. Plepys and R. J. Farris, "Evolution of residual stresses in three-dimensionally constrained epoxy resins," Polymer, vol. 31, no. 10, pp. 1932-1936, Oct. 1990, doi: 10.1016/0032-3861(90)90019-U.

[20] A. Plepys, M. S. Vratsanos, and R. J. Farris, "Determination of residual stresses using incremental linear elasticity," Composite Structures, vol. 27, no. 1, pp. 51-56, Jan. 1994, doi: 10.1016/02638223(94)90066-3.

[21] T. A. Bogetti and J. John W. Gillespie, "Process-Induced Stress and Deformation in ThickSection Thermoset Composite Laminates:", Journal of Composite Materials, Jul. 2016, doi: $10.1177 / 002199839202600502$.

[22] J. T. Zhang, M. Zhang, S. X. Li, M. J. Pavier, and D. J. Smith, "Residual stresses created during curing of a polymer matrix composite using a viscoelastic model," Composites Science and Technology, vol. 130, pp. 20-27, Jun. 2016, doi: 10.1016/j.compscitech.2016.05.002. 
[23] A. Ding, S. Li, J. Wang, and L. Zu, "A three-dimensional thermo-viscoelastic analysis of processinduced residual stress in composite laminates," Composite Structures, vol. 129, pp. 60-69, Oct. 2015, doi: 10.1016/j.compstruct.2015.03.034.

[24] D. B. Adolf and R. S. Chambers, "A thermodynamically consistent, nonlinear viscoelastic approach for modeling thermosets during cure," Journal of Rheology, vol. 51, no. 1, pp. 23-50, Jan. 2007, doi: 10.1122/1.2360670.

[25] J. Lange, S. Toll, J.-A. E. Månson, and A. Hult, "Residual stress build-up in thermoset films cured below their ultimate glass transition temperature," Polymer, vol. 38, no. 4, pp. 809-815, Feb. 1997, doi: 10.1016/S0032-3861(96)00584-8.

[26] S. R. White and H. T. Hahn, "Process Modeling of Composite Materials: Residual Stress Development during Cure. Part I. Model Formulation," Journal of Composite Materials, vol. 26, no. 16, pp. 2402-2422, Jan. 1992, doi: 10.1177/002199839202601604.

[27] C. Heinrich, M. Aldridge, A. S. Wineman, J. Kieffer, A. M. Waas, and K. W. Shahwan, "Generation of heat and stress during the cure of polymers used in fiber composites," International Journal of Engineering Science, vol. 53, pp. 85-111, 2012.

[28] C. Heinrich, M. Aldridge, A. S. Wineman, J. Kieffer, A. M. Waas, and K. W. Shahwan, "The role of curing stresses in subsequent response, damage and failure of textile polymer composites," Journal of the Mechanics and Physics of Solids, vol. 61, no. 5, pp. 1241-1264, May 2013, doi: 10.1016/j.jmps.2012.12.005.

[29] R. J. D'Mello and A. M. Waas, "Virtual curing of textile polymer matrix composites," Composite Structures, vol. 178, pp. 455-466, Oct. 2017, doi: 10.1016/j.compstruct.2017.05.045.

[30] E. Ruiz and F. Trochu, "Thermomechanical Properties during Cure of Glass-Polyester RTM Composites: Elastic and Viscoelastic Modeling," Journal of Composite Materials, vol. 39, no. 10, pp. 881916, May 2005, doi: 10.1177/0021998305048732.

[31] Y. Abou Msallem, F. Jacquemin, N. Boyard, A. Poitou, D. Delaunay, and S. Chatel, "Material characterization and residual stresses simulation during the manufacturing process of epoxy matrix composites," Composites Part A: Applied Science and Manufacturing, vol. 41, no. 1, pp. 108-115, Jan. 2010, doi: 10.1016/j.compositesa.2009.09.025.

[32] C. Billotte, F. M. Bernard, and E. Ruiz, "Chemical shrinkage and thermomechanical characterization of an epoxy resin during cure by a novel in situ measurement method," European Polymer Journal, vol. 49, no. 11, pp. 3548-3560, Nov. 2013, doi: 10.1016/j.eurpolymj.2013.07.013.

[33] A. S. Ganapathi, S. C. Joshi, and Z. Chen, "Influence of cure kinetic, rheological and thermomechanical behavior on micro-level curing strain of an epoxy prepreg," J Therm Anal Calorim, vol. 124, no. 1, pp. 305-316, Apr. 2016, doi: 10.1007/s10973-015-5090-2.

[34] L. Khoun, T. Centea, and P. Hubert, "Characterization Methodology of Thermoset Resins for the Processing of Composite Materials - Case Study: CYCOM 890RTM Epoxy Resin," Journal of Composite Materials, vol. 44, no. 11, pp. 1397-1415, Jun. 2010, doi: 10.1177/0021998309353960.

[35] J. Puentes, J. L. Colon Quintana, A. Chaloupka, N. Rudolph, and T. A. Osswald, "Moduli development of epoxy adhesives during cure," Polymer Testing, vol. 77, p. 105863, Aug. 2019, doi: 10.1016/j.polymertesting.2019.04.010.

[36] M. Sadeghinia, K. M. B. Jansen, and L. J. Ernst, "Characterization of the viscoelastic properties of an epoxy molding compound during cure," Microelectronics Reliability, vol. 52, no. 8, pp. 1711-1718, Aug. 2012, doi: 10.1016/j.microrel.2012.03.025. 
[37] A. T. DiBenedetto, "Prediction of the glass transition temperature of polymers: A model based on the principle of corresponding states," Journal of Polymer Science Part B: Polymer Physics, vol. 25, no. 9, pp. 1949-1969, 1987, doi: 10.1002/polb.1987.090250914.

[38] G. M. Odegard and A. Bandyopadhyay, "Physical aging of epoxy polymers and their composites," Journal of Polymer Science Part B: Polymer Physics, vol. 49, no. 24, pp. 1695-1716, 2011, doi: https://doi.org/10.1002/polb.22384.

[39] D. J. O'Brien and S. R. White, "Cure kinetics, gelation, and glass transition of a bisphenol F epoxide," Polymer Engineering \& Science, vol. 43, no. 4, pp. 863-874, 2003, doi: 10.1002/pen.10071.

[40] L. Khoun and P. Hubert, "Cure shrinkage characterization of an epoxy resin system by two in situ measurement methods," Polymer Composites, vol. 31, no. 9, pp. 1603-1610, 2010, doi: 10.1002/pc.20949.

[41] K. F. Schoch, P. A. Panackal, and P. P. Frank, "Real-time measurement of resin shrinkage during cure," Thermochimica Acta, vol. 417, no. 1, pp. 115-118, Jul. 2004, doi: 10.1016/j.tca.2003.12.027.

[42] M. Zarrelli, A. A. Skordos, and I. K. Partridge, "Investigation of cure induced shrinkage in unreinforced epoxy resin," Plastics, Rubber and Composites, vol. 31, no. 9, pp. 377-384, Nov. 2002, doi: $10.1179 / 146580102225006350$.

[43] C. Li, K. Potter, M. R. Wisnom, and G. Stringer, "In-situ measurement of chemical shrinkage of MY750 epoxy resin by a novel gravimetric method," Composites Science and Technology, vol. 64, no. 1, pp. 55-64, Jan. 2004, doi: 10.1016/S0266-3538(03)00199-4.

[44] H. Yu, S. G. Mhaisalkar, and E. H. Wong, "Cure shrinkage measurement of nonconductive adhesives by means of a thermomechanical analyzer," Journal of Elec Materi, vol. 34, no. 8, pp. 11771182, Aug. 2005, doi: 10.1007/s11664-005-0248-5.

[45] E37 Committee, "Test Method for Linear Thermal Expansion of Solid Materials by Thermomechanical Analysis,” ASTM International. doi: 10.1520/E0831-19.

[46] D30 Committee, "Test Method for Glass Transition Temperature (DMA Tg) of Polymer Matrix Composites by Dynamic Mechanical Analysis (DMA)," ASTM International. doi: 10.1520/D7028-07E01.

[47] OriginLabs Corporation, Origin (Pro), Version 2020b. Northampton, MA, USA: OriginLab Corporation.

[48] Simulia Corp, Dassault Systemes, Abaqus 6.16 Documentation. Simulia Corp, 2016. [Online]. Available: http://dsk.ippt.pan.pl/docs/abaqus/v6.16/index.html 